\title{
ADAPTABILIDADE DE MUDAS MICROPROPAGADAS DE ABACAXIZEIRO NO NORDESTE DO ESTADO DE MATO GROSSO
}

\section{ADAPTABILITY OF MICROPROPAGED SEEDLINGS OF PINEAPPLE IN THE NORTHEAST OF MATO GROSSO STATE}

\author{
Marcela Martins Aragão ${ }^{1}$ (D), Josiane Lopes $\operatorname{Neves}^{2}$ (D), José Antônio Do Vale Sant' Ana ${ }^{3}$ (D)
}

Recebido em 15 de Outubro de 2020 | Aprovado em 16 de dezembro de 2020

\begin{abstract}
RESUMO
O abacaxi (Ananas comosus L., Merril) é uma planta de clima tropical de grande importância econômica para o Brasil, o terceiro maior produtor mundial. O estudo sobre aclimatação de mudas micropropagadas de abacaxi ainda é escasso, tendo poucos trabalhos relacionados ao tema publicados, sendo assim, o presente trabalho teve como objetivo avaliar adaptação de mudas micropropagadas das cultivares BRS Imperial e BRS Vitória no município de Confresa-MT. O projeto foi conduzido na casa de sombra do IFMT Campus Confresa, onde o plantio foi realizado em sacos plásticos, com uma mistura de substrato e areia. O delineamento experimental utilizado foi o inteiramente casualizado, com dois tratamentos e vinte repetições. Sendo os tratamentos as cultivares BRS Imperial e BRS Vitória. Entre os meses de novembro de 2019 e julho de 2020 foram coletadas as medidas da altura de plantas, observando o desenvolvimento das mudas em relação a adaptação às condições climáticas da região e resistência a doenças. As mudas foram adubadas com N-P-K diluído em água e fertilizante foliar; a irrigação era realizada conforme a necessidade acusada pelo Irrigás. Houve adaptabilidade para ambas as mudas de abacaxizeiro tendo 'BRS Imperial' apresentado menor crescimento e maior resistência a doenças em relação às mudas da 'BRS Vitória'.
\end{abstract}

Palavras-chave: Ananas comosus L; cultivares; clima; Nordeste Mato-Grossense.

\begin{abstract}
Pineapple (Ananas comosus L., Merril) is a tropical climate plant of great economic importance for Brazil, the third largest world producer. The study on acclimatization of pineapple micropropagated seedlings is still scarce, with few studies related to the published theme, therefore, the present study aimed to evaluate adaptation of micropropagated seedlings of the cultivars BRS Imperial and BRS Vitória in the municipality of Confresa-MT. The project was carried out in the shade house of the IFMT Campus Confresa, where the planting was carried out in plastic bags, with a mixture of substrate and sand. The experimental design used was completely randomized, with two treatments and twenty repeated. The treatments were the cultivars BRS Imperial and BRS Vitória. Between the months of November 2019 and July 2020, measurements of plant height were collected, observing the development of seedlings in relation to adaptation to the climatic conditions of the region and resistance to diseases. The seedlings were fertilized with N-P-K diluted in water and foliar fertilizer; irrigation was carried out according to the needs indicated by Irrigás. There was adaptability for both pineapple seedlings, with BRS Imperial showing lower growth and greater resistance to diseases compared to the seedlings of BRS Vitória.
\end{abstract}

Keywords: Ananas comosus L; cultivars; climate; Northeast Mato-Grossense.

\footnotetext{
${ }^{1}$ Graduanda em Agronomia (IFMT - Campus Confresa), Confresa, Mato Grosso, Brasil. Rua Santo Antônio, $\mathrm{n}^{\circ}$ 26, Jardim Planalto, Confresa, Mato Grosso, Brasil, CEP: 78652-000. E-mail: josianelopes.neves@gmail.com.

${ }^{2}$ Graduanda em Agronomia (IFMT - Campus Confresa), Confresa, Mato Grosso, Brasil. Rua Castelo Branco, $\mathrm{n}^{\circ}$ 11, Centro, Confresa, Mato Grosso, Brasil, CEP: 78652-000. E-mail: marcelaaragao01@gmail.com.

${ }^{3}$ Doutor em Recursos Hídricos em Sistemas Agrícolas pela Universidade Federal de Lavras (UFLA) Professor no Instituto Federal de Educação, Ciência e Tecnologia Campus Confresa (IFMT - Campus Confresa), Confresa, Mato Grosso, Brasil. Rua José Pereira Fernandes, $n^{\circ} 42$, Morada Nova, Confresa, Mato Grosso, Brasil, CEP: 78652-000. E-mail: jose.santana@cfs.ifmt.edu.br.
} 


\section{Introdução}

Os abacaxizeiros de maior importância no cultivo brasileiro, pertencem à espécie (Ananas comosus L., Merril) que são importantes tanto para o consumo in natura como para o industrializado (MANICA, 2000). O Ananas comosus é uma planta monocotiledônea, herbácea perene, da família Bromeliaceae (REINHARDT, 2000).

É uma planta de clima tropical, originária de regiões de clima quente e seco ou com chuvas irregulares. Apresentando crescimento ótimo e melhor qualidade do fruto na faixa de temperatura de 21 a $32{ }^{\circ} \mathrm{C}$, sendo que temperaturas acima de $40^{\circ} \mathrm{C}$ e abaixo de $5^{\circ} \mathrm{C}$ causam distúrbios fisiológicos na planta (SOUZA et al., 2017).

O Brasil é líder na produção de abacaxi, ocupando o terceiro lugar no plano com um volume de 2,3 milhões de toneladas produzidas em 2017. É notável um crescimento constante da área de abacaxi cultivada e sua produção total, sendo que até o ano de 2017 a área colhida dobrou e a produtividade por hectare triplicou, resultando num aumento da produção em cinco vezes maior (REINHARDT, 2019).

No entanto, para que ocorra a maior expansão da abacaxicultura alguns fatores de produção devem ser estudados para que atividade seja realizada com maior eficiência. Sendo o uso de novas tecnologias, como novas cultivares fatores que contribui significativamente para o aprimoramento e potencialização dessa atividade.

Com a necessidade de obtenção de novas cultivares, programas de melhoramento genético procuram desenvolver cultivares superiores de abacaxizeiro com características físicoquímicas e sensoriais adequadas ao desejo mercado interno e externo, e resistência à fusariose (SILVA, 2018).

As cultivares BRS Imperial e BRS Vitória foram lançadas recentemente e possuem como principal vantagem a resistência a fusariose, doença que pode ser tonar fator limitante para a produção do abacaxi em algumas regiões, além de possuir boa qualidade dos frutos com boa aceitação no mercado consumidor.

A cultivar BRS Imperial, por ser resistente à fusariose foi recomendada, pela Embrapa Mandioca e Fruticultura Tropical, para plantio em regiões adequadas à abacaxicultura, principalmente onde a fusariose e fator limitante (MATOS et al., 2006).

De acordo com Sanches e Matos (2013), a 'BRS Imperial' é o resultado do cruzamento entre as cultivares 'Perolera' e 'Smooth Cayenne', além de ser resistente a fusariose ela também apresenta resistência ao escurecimento interno do fruto, o que é uma grande vantagem para 
produtores interessados na exportação. Suas folhas são desprovidas de espinhos exceto na ponta, facilitando seu manejo.

Já a cultivar BRS Vitória é uma das mais recomendadas para a região Mato-grossense por apresentar boas características produtivas como qualidade do fruto e resistência à fusariose (TODA FRUTA, 2016). A 'BRS Vitória' é fruto do cruzamento entre as cultivares 'Primavera' e Smooth Cayenne', seus frutos apresentam formato cilíndricos, possui a polpa branca, reduzido diâmetro do eixo central, boa suculência e elevado teor de açúcar. Suas folhas são lisas sem espinho, o que facilita os tratos culturais (SANCHES; MATOS, 2013)

Ciente da importância da introdução de novas cultivares na atividade abacaxícola na região, o presente trabalho teve como objetivo avaliar adaptação de mudas micropropagadas das cultivares BRS Imperial e BRS Vitória no município de Confresa-MT.

\section{Metodologia}

O experimento foi conduzido na casa de sombra do Instituto Federal de Educação Ciência e Tecnologia de Mato Grosso - Campus Confresa, latitude $10^{\circ} 38^{\prime} 38^{\prime \prime}$ 'sul, longitude $51^{\circ} 34^{\prime} 08$ " oeste com altitude de 240 m, no Nordeste do Estado de Mato Grosso. Para a condução do estudo foram usadas mudas de abacaxi (Ananas comosus L. Merril) das cultivares BRS Imperial e BRS Vitória, recomendadas para o clima e solo mato-grossense. O delineamento experimental utilizado foi o inteiramente casualizado com vinte repetições. Sendo os tratamentos as cultivares BRS Imperial e BRS Vitória.

As mudas foram obtidas de uma empresa privada que atua na área de Biotecnologia Vegetal e fornecem mudas de alta qualidade fitossanitária. O plantio foi realizado em sacos plásticos próprios para mudas, composto por uma mistura de substrato + areia, no dia 21 de novembro de 2019. Foram instalados sensor Irrigás nos saquinhos, para que indicasse a necessidade de realizar a irrigação das mudas.

As mudas foram colocadas em bancadas de madeira, dentro da casa de sombra, sob uma estrutura de plástico. A estrutura foi retirada quando as mudas ficaram maiores. Após a retirada da estrutura, as mudas foram cobertas com sombrite para evitar queima pelo sol e protegê-las das fortes chuvas que ocorriam durante os primeiros meses após o plantio.

As adubações, inicialmente, foram feitas com N-P-K diluído em água e aplicado com o auxílio de uma pipeta. Com o crescimento das mudas, o adubo foi trocado para um específico para frutíferas, utilizando adubo foliar aplicado através da pulverização a cada dois meses nas mudas. 
No período de novembro a julho avaliou-se a seguinte característica:

Altura de plantas: com o auxílio de uma régua mediu-se a altura das plantas, foram escolhidas aleatoriamente 20 plantas de cada cultivar e retirada as medidas.

Os dados foram submetidos à análise de variância com significância a 5\% de probabilidade no Software SISVAR e utilizou teste Tukey (5\%) para comparação das médias, bem como a regressão para descrição do desenvolvimento das mudas ao longo dos meses de avaliação.

\section{Resultados e Discussão}

Verificou-se diferença significativa entre as alturas das duas cultivares, como apresentado no resumo do quadro de análise variância na Tabela 1.

Tabela 1 -Resumo do quadro de análise variância para altura de plantas.

\begin{tabular}{ccc}
\hline F.V & G.L & QUADRADO MÉDIO \\
\cline { 3 - 3 } & & ALTURA $(\mathrm{cm})$ \\
\hline CULTIVAR & 1 & $84,46^{*}$ \\
ERRO & 18 & 9,17 \\
\hline CV(\%) & 23,58 & \\
\hline
\end{tabular}

*Significativo pelo teste "F" a 5\% de probabilidade.

Fonte: Aragão; Neves; Sant'Ana, 2020.

Araújo (2013) comparando seu estudo com a cultivar Imperial com o de Berilli et al. (2011) com a cultivar Vitória, observou que as mudas de abacaxizeiro da cultivar Vitória provenientes dos estádios 2 (60 dias), 3 (90 dias) e 4 (120 dias) apresentaram após período de aclimatação de 150 dias, valores médios de altura muito próximos, em torno de $22 \mathrm{~cm}$.

Diferentemente do que aconteceu neste estudo, no qual os valores médios obtidos foram bem menores para as duas cultivares. A cultivar 'BRS Vitória' apresentou maior média de altura como apresentado na tabela 2. E conforme Cabral; Matos (2005), o crescimento lento está entre as características consideradas desfavoráveis na cultivar Imperial. 
Tabela 2 -Altura média de planta em cm de mudas de abacaxizeiro das cultivares BRS Imperial e BRS Vitória.

\begin{tabular}{lc}
\hline Cultivares & Altura de planta(cm) \\
\hline BRS Imperial & $10,79 \mathrm{~b}$ \\
BRS Vitória & $14,90 \mathrm{a}$ \\
\hline
\end{tabular}

Fonte: Aragão; Neves; Sant'ana, 2020.

As mudas da 'BRS Imperial' apresentaram 10,79 cm para altura de planta, enquanto a 'BRS Vitória' apresentou 14,90 cm de altura de planta. É provável que as mudas que apresentaram maiores alturas tenham tido uma melhor adaptação às condições climáticas da região, ao substrato ultilizado e as adubações realizadas.

Entretando, é importante salientar que mudas de abacaxizeiro micropopagadas apresentam crescimento bastante lento durante a fase de aclimatação e dependendo do substrato e da nutrição das plantas pode levar mais tempo (FOLLIOT; MARCHAL, 1990 apud WEBER et al., 2013).

Gráfico 1. Altura das cultivares de abacaxi ‘BRS Imperial'e 'BRS Vitória' durante os meses de avaliação. Confresa, 2020.

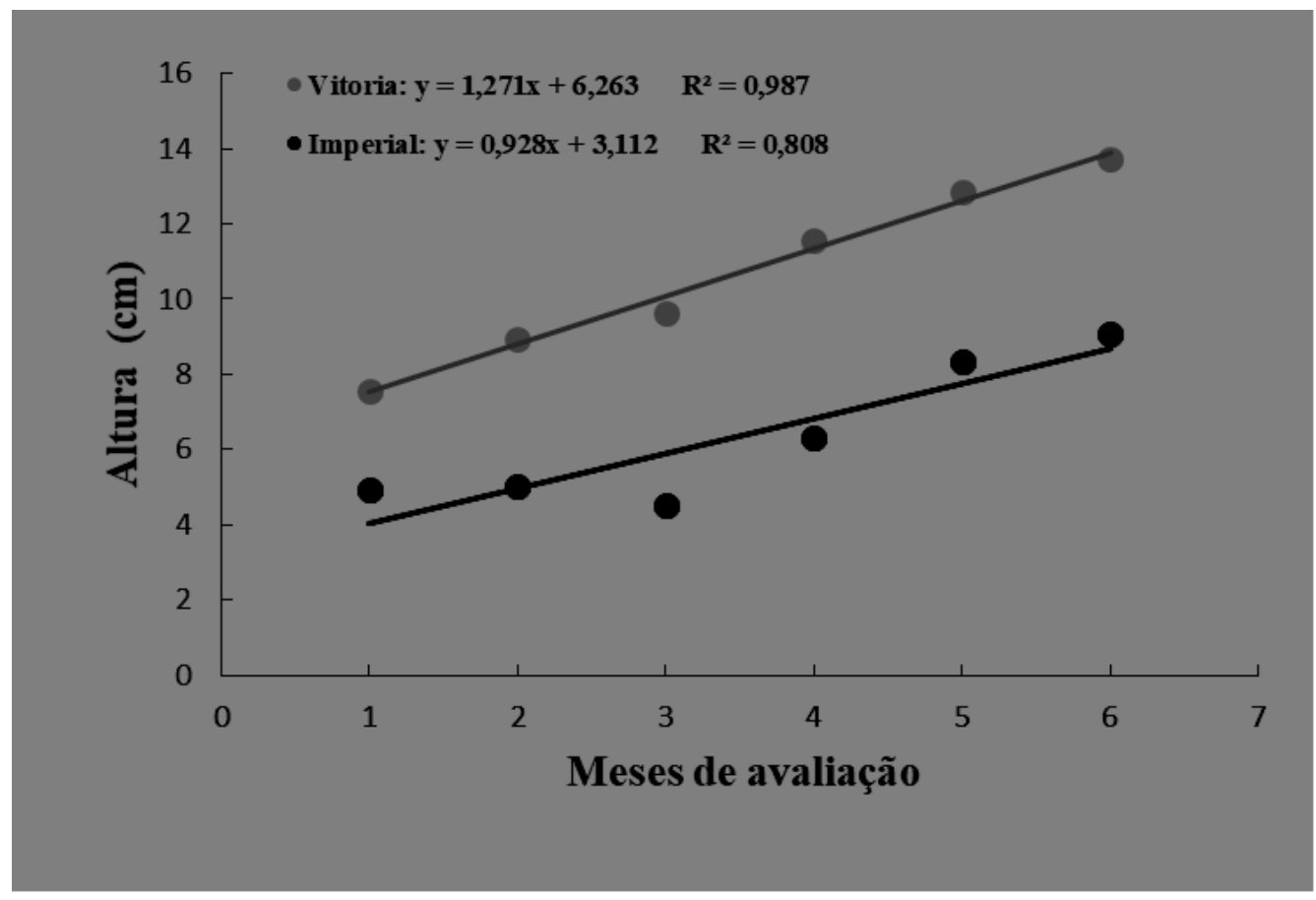

Fonte: Aragão; Neves; Sant’ana, 2020.

No Gráfico 1, pode-se observar que durante todos os meses de avaliação as mudas da cultivar 'BRS Vitória', apresentaram as maiores alturas. Isso indica uma provável vantagem na 
adaptabilidade das mudas da 'BRS Vitória' em relação as mudas 'BRS Imperial' que obtiveram pior desenvolvimento quando comparada com a outra cultivar.

No entanto, a cultivar 'BRS Vitória' apresentou maior susceptibilidade para a doença mancha-amarela. Pois, as duas cultivares estavam na mesma bancada, porém, não houve transmissão da doença para a 'BRS Imperial', doença essa que contaminou as mudas da 'BRS Vitória' causando morte de plantas.

A mancha-amarela é uma doença de etiologia viral que pode infectar o fruto e a planta do abacaxizeiro, no entanto, esta doença não apresenta ameaça para a cultura do abacaxi. Porém, é importante ressaltar que esta doença tem ocorrência em níveis variáveis de suscetibilidade entre os diferentes materiais propagativos (BARBOSA; BIANCHI, 2014).

De acordo com Feitosa (2010), outro fator importante que pode ocorrer em mudas micropropagadas são as variações somaclonais, fator este que pode ter favorecido a susceptibilidade a mancha-amarela doença que até então não possui relevância na cultura do abacaxi.

Já as mudas da 'BRS Imperial' tiveram um crescimento lento e uniforme. Esse baixo crescimento pode estar relacionado a baixa eficiência do substrato utilizado para o estudo das cultivares. Araújo (2013), testando diferentes substratos em aclimatação de mudas micropropagadas com a 'BRS Imperial', verificou que há influência sob o uso de diferentes substratos na taxa de crescimento absoluto das mudas.

Incialmente, a 'BRS Imperial' obteve crescimento inferior quando estava sob a estrutura de plástico, se comparado com os meses após a retirada da estrutura. No entanto, essa cultivar sempre apresentou menores altura em relação a 'BRS Vitória' que sempre obteve um maior crescimento independente do ambiente.

\section{Análises e Resultados}

As mudas micropropagadas de abacaxi das cultivares BRS Vitória e BRS Imperial são uma boa opção para produtores que enfrentam problemas com a fusariose, porém, exige um estudo mais aprofundado dessas cultivares na região que seja conclusivo em relação ao melhor substrato utilizado durante o período de aclimatação, a melhor adubação e a suscetibilidade à doenças que incidem na região.

Apesar da incidência da mancha amarela na cultivar BRS Vitória durante esse estudo, um novo estudo em condições diferentes poderia demonstrar todo o potencial genético dessa cultivar na região de Confresa, bem como identificar as causas do lento crescimento inicial da 
cultivar BRS Imperial.

\section{Considerações}

As mudas micropropagadas de abacaxizeiro ('BRS Imperial' e 'BRS Vitória') têm boa adaptação no município de Confresa e região, no entanto, a cultivar BRS Imperial apresenta maior resistência a incidência de doenças, como mancha amarela, doença que atacou com severidade a cultivar BRS Vitória.

\section{Agradecimentos}

Ao Instituto Federal de Educação, Ciência e Tecnologia de Mato Grosso - Campus Confresa pelo apoio, financiamento do projeto e concessão da bolsa (Programa PROIC/IFMT).

\section{Referências}

ARAÚJO, V. L. Aclimatização e aclimatação de mudas de abacaxizeiro (Ananas comosus L. var. comosus) cv. Imperial em substratos orgânicos e comercial. 2013. 117f.

Dissertação (Mestrado em Agronomia) - Centro de Ciências Agrárias. Universidade Federal da Paraíba, Areia, 2013.

BARBOSA, K. M.; BIANCHI R. Principais doenças do abacaxi. Etimologia, Sintoma e Controle. Centro Universitário do Rio Preto, 2014.

BERILLI, S. DA S. et al. Crescimento de mudas de abacaxizeiro cv. vitória durante a aclimatação em função do seu tamanho inicial. Revista Brasileira de Fruticultura. São Paulo, Jaboticabal, 2011.

CABRAL, J. R. S; MATOS, A.P de. Imperial, nova cultivar de abacaxi. Comunicado Técnico 114. Cruz das Almas, BA, 2005. Disponível em:

$<$ http://www.sbwbrasil.com.br/pdf/CM_114_Imperial.pdf $>$. Acessado em: 14 out. 2020.

MATOS, A. P. de et al. A cultura do abacaxi. 2. ed. rev. amp. Brasília: Embrapa Informação Tecnológica, 2006. $91 \mathrm{p}$.

FEITOSA, H. O. Crescimento e extração de nutrientes pelo abacaxizeiro cv. Vitoria sob doses crescente de micronutrientes em tipo de cobertura de solo. 2010. 108f. Conclusão de Curso (Pós-graduação em engenharia agrícola) - Universidade Federal do Ceará, Fortaleza, 2010.

FERREIRA, D. F. Sisvar: a computer statistical analysis system. Ciência e Agrotecnologia (UFLA), v. 35, n.6, p. 1039-1042, 2011. Disponível em: $<$ https://www.scielo.br/scielo.php?pid=S1413-70542011000600001\&script $=$ sci_arttext $>$. Acessado em: 06 de oct. 2020. DOI: https://doi.org/10.1590/S1413-70542011000600001. 
MANICA, I. Abacaxi: do plantio ao mercado. 1. Porto Alegre: Cinco Continentes, 2000. $122 \mathrm{p}$.

PESQUISA avalia a melhor época de colheita do abacaxi em. Toda Fruta, 2016. Disponível em: $<$ https://www.todafruta.com.br/mt-pesquisa-avalia-a-melhor-epoca-de-colheita-doabacaxi-em-mato-grosso/>. Acessado em: 03 mar. 2020.

REINHARDT, D. H.; SOUZA, LF da S.; JRS (ORG.) CABRAL. A planta e seu ciclo. In: REINHARDT, DHRC. Abacaxi produção: aspectos técnicos. Brasília: Embrapa Comunicação para Transferência de Tecnologia, 2000. 77 p.

REINHARDT, DHRC. A cultura do abacaxizeiro: tradição e inovação. Embrapa Mandioca e Fruticultura-Capítulo em livro técnico, v.3, p. 80-96, junho. 2019.

SANCHES, N. F.; DE MATOS, A. P. Abacaxi: o produtor pergunta, a Embrapa responde.2. ed. rev. atual. Ampl. Brasília: Embrapa, 2013. 191 p.

SILVA, C. N. Desenvolvimento de mudas micropropagadas do abacaxizeiro cv. brs vitória submetidas a adubação foliar com ureia em condições protegidas. 2018. 34f. Trabalho de Conclusão de Curso (Graduação em Agronomia) - Universidade Federal de Roraima, Boa Vista, 2018.

SOUZA, FVD et al. Abacaxi (Ananas spp.). Abacaxizeiros (Ananas spp.) cultivados e silvestres. Instituto Interamericano de Cooperación para la Agricultura (IICA), 2017. 31 p.

WEBER, O. B. et al. Efeito da bactéria diazotrófica em mudas micropropagadas de abacaxizeiros Cayenne Champac em diferentes substratos. Pesquisa Agropecuária Brasileira, v. 38, n. 6, p. 689-696, 2003. Disponível em: $<$ https://www.scielo.br/scielo.php?pid=S0100204X2003000600004\&script $=$ sci_arttext\&tlng $=$ pt $>$. Acessado em: 08 out. 2020. DOI: https://doi.org/10.1590/S0100-204X2003000600004. 